\title{
ASSESSMENT OF SHEAR STRENGTH IN SILTY SOILS
}

\author{
KATARZYNA STEFANIAK \\ Poznań University if Life Sciences, Institute of Construction and Geoengineering, \\ ul. Wojska Polskiego 28, 60-637 Poznań, Poland, e-mail: katarzyna.stefaniak@up.poznan.pl
}

\begin{abstract}
The article presents a comparison of shear strength values in silty soils from the area of Poznan, determined based on selected $N_{k t}$ values recommended in literature, with values of shear strength established on the basis of $N_{k t}$ values recommended by the author. Analysed silty soils are characterized by the carbonate cementation zone, which made it possible to compare selected empirical coefficients both in normally consolidated and overconsolidated soils.
\end{abstract}

Key words: shear strength, cone factor $N_{k}$, silty soils

\section{INTRODUCTION}

Shear strength $\left(s_{u}\right)$ is a basic parameter determining engineering suitability of soils. Shear strength is determined using constitutive laws or alternatively applying empirical dependencies. In the case of silty soils it is problematic to assess shear strength $s_{u}$ under laboratory conditions, when the realisation of stress and strain paths may lead to different $s_{u}$ values [1]. This is mainly connected with the preparation of high quality soil samples, as a consequence leading to increased interest in the methods of in situ testing. However, empirical dependencies used in the interpretation of in situ testing need to be calibrated, particularly in cone penetration tests CPTU [2]-[4]. The problem related to different $s_{u}$ values provided by CPTU test is connected with an appropriate selection of the empirical coefficient $N_{k t}$. In practice, reference tests are frequently neglected, thus problems appear with the divergent shear strength values.

This study focused on cone penetration test and the assumed values of the empirical cone factor $N_{k t}$. Moreover, based on the tests conducted on silty soils this paper proposes values of empirical coefficients $N_{k t}$ recommended for silty soils.

\section{SELECTED METHODS TO DETERMINE SHEAR STRENGTH}

Shear strength may be provided in laboratory analyses in a triaxial compression apparatus and direct shear apparatus. These tests were conducted using standard procedures, while most commonly testing results are interpreted using the Coulomb-Mohr hypothesis, with which shear strength parameters are identified in designing building foundations.

Laboratory analyses are burdened with certain limitations. The first problem we face when performing laboratory analyses is connected with the preparation of high quality soil samples. Apart from problems related to in situ soil sampling, the primary drawback of laboratory tests results frequently from the insufficient volume of the samples being examined. In the last two decades, thorough studies on sample quality and the criterion of sample quality have been conducted in numerous centres, e.g., the Norwegian Geotechnical Institute (NGI).

Despite many drawbacks, laboratory analyses are the basic sources of information on geotechnical parameters of soils. In the case of a complex subsoil structure or soils with poor bearing capacity, including silty soils, strength parameters should be assessed based both on laboratory and in situ testing. In silty soils the most frequently applied in situ testing methods include vane tests (VT) and cone penetration tests probing (CPTU).

Based on the results of cone penetration tests the value of undrained shear strength may be calculated from equation (1), which most typically refers to shear strength from the vane test or from the direct shear test and it is determined using the net cone resistance value $\left(q_{n}\right)$.

$$
s_{u}=\frac{q_{n}}{N_{k t}}
$$


where $N_{k t}$ - empirical cone factor, dependent on soil characteristics.

In turn, Senneset et al. [5] in cases when a test is performed with measurements of pore water pressure suggested the use of equation (2)

$$
s_{u}=\frac{q_{t}-u_{2}}{N_{k e}}
$$

where $q_{t}$ - corrected cone resistance, $u_{2}$ - pore water pressure measured on the cone, $N_{k e}$ - empirical cone factor (for the expression using $q_{t}$ ).

The value of empirical cone factor $N_{k t}$ is strongly dependent on the concept for the description of undrained shear strength in laboratory testing, which is to simulate subsoil loading conditions. This situation is very well illustrated by Fig. 1 [3].

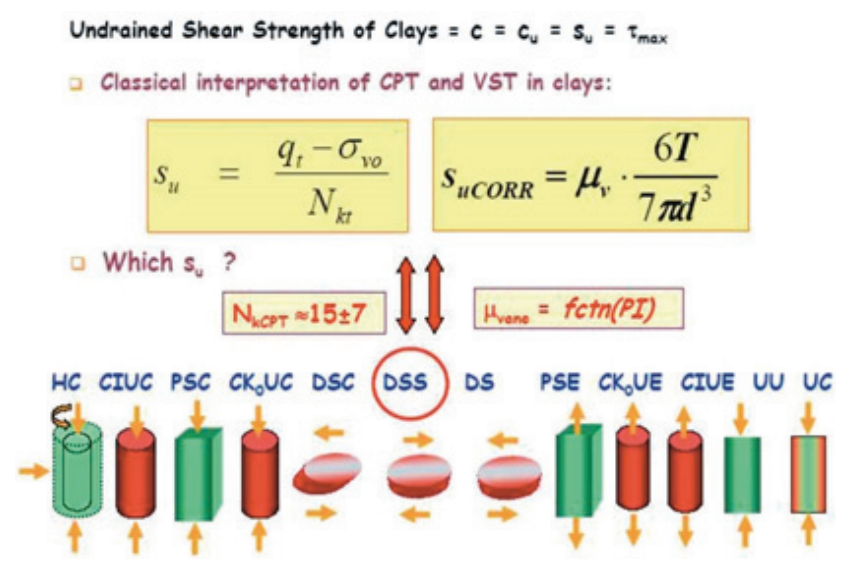

Fig. 1. Determination of shear strength $s_{u}$ from laboratory analysis in the direct shear test DSS, the triaxial shear test TXT or cone penetration test CPT, vane testing VT [3]

The problem connected with divergent values of soil shear strength $\left(s_{u}\right)$ was presented, e.g., by DeGroott and Lutenegger [6], as shown in Fig. 2.

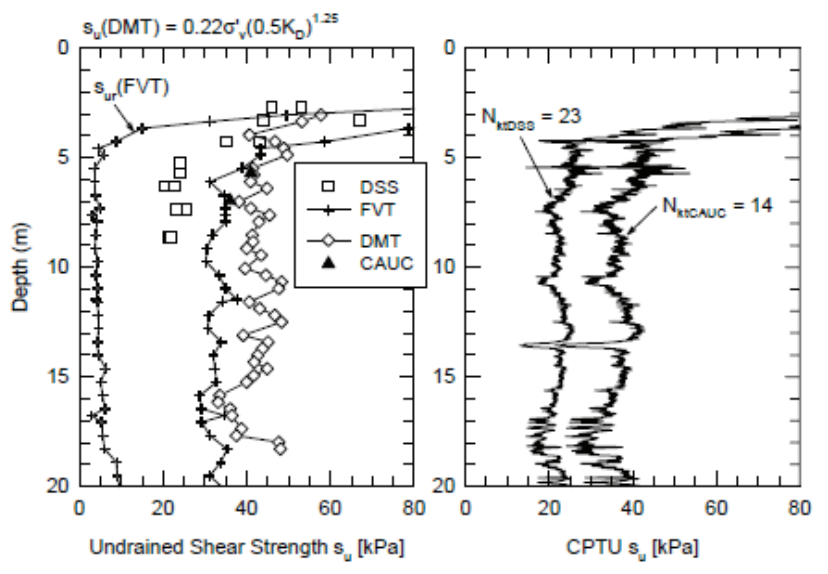

Fig. 2. Undrained shear strength data from laboratory recompression tests (DSS, CAUC) and in situ tests (FVT, DMT, CPTU) [6]
Determination of these parameters is closely dependent on the method of experimentation, which should reconstruct changes in the state of stress in the subsoil as a result of expected subsoil loading by the building structure.

As reported in literature sources on the subject, values of $N_{k t}$ fall within the range of 10-20. For this reason it seems justified to verify this coefficient based on available archival materials for a given area or additional laboratory analyses in the triaxial shear test TXT or vane testing VT. The graph given in Fig. 3 may also be useful in this respect [7]. Aas and coworkers [7] presented dependencies between the correlation $N_{k t}$ and the plasticity index. In turn, La Rochelle et al. [8] showed that the scope of $N_{k t}$ falls within the range from 11 to 18 .

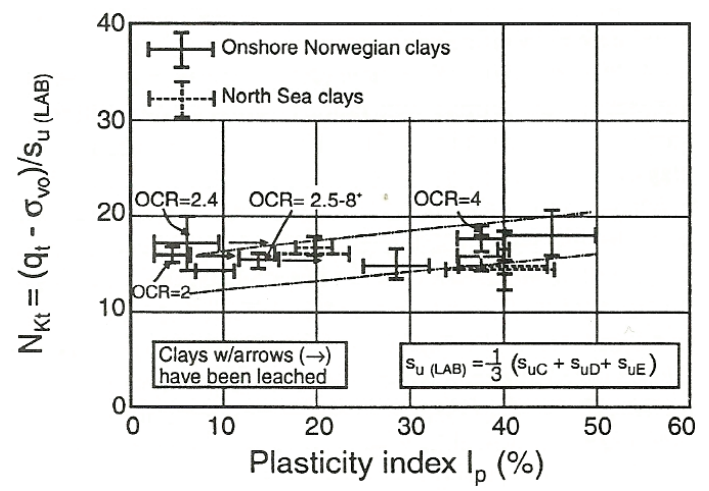

Fig. 3. A dependence between the determined $N_{k t}$ and plasticity index [7]

Similar values of $N_{k t}$ were obtained by Powell and Quarterman [9] based on laboratory analyses in the triaxial shear tests, showing that values of $N_{k t}$ range from 10 to 20 .

As reported by Młynarek and Wierzbicki [4], normally consolidated and slightly overconsolidated soils may take values of $N_{k t}$ close to 10 , while this coefficient in strongly overconsolidated deposits may be as high as 30 . In the case of soft-plastic deposits, almost liquid, in which the accuracy of cone resistance measurement is low, measured values of excess pore water pressure $\Delta u$ need to be used, assuming $N_{u}$ to range from 7 and 10 (equation (3)).

$$
s_{u}=\frac{\Delta u}{N_{\Delta u}}=\frac{u_{2}-u_{0}}{N_{\Delta u}}
$$

where $\Delta u$ - excess pore water pressure, $u_{0}$ - in situ pore pressure, $N_{u}$ - cone factor.

In the case of vane test VT, which makes it possible to determine shear strength in soft soils, it is frequently recommended to apply correction coefficients $\mu$. This coefficient changes depending on the type of test, to 
which we intend to refer the obtained results, soil type or the time factor.

According to Bjerrum [10] the use of results provided by the field vane test for weak silts for practical purposes requires the application of correction coefficients. Corrected undrained shear strength may be determined with the following equation (4) [10]

$$
s_{u \mathrm{corr}}=s_{u(V T)} \cdot \mu_{R}-\mu_{A}
$$

where $\mu_{R}$ - correction coefficient, including the effect of time, by Bjerrum [10] should be selected depending on the length of the period, $\mu_{A}-$ correction coefficient including silt anisotropy.

Lechowicz and co-workers [11] recommended the correction coefficient ranging from 0.51 to $0.61 \mathrm{de}$ pending on the type of organic soil.

For researchers a frequently problematic issue in the case of CPTU and VT is to appropriately refer the results to a respective laboratory analysis. This is connected, e.g., with the fact that CPTU and VT describe different theoretical solutions. If an illustration is very small, you may impose the caption or continue the text next to it, and the rule is that it should be placed in the left part of even-numbered pages, and in the right part of odd-numbered pages.

\section{CHARACTERISTICS OF ANALYSED SILTY SOILS}

Analyses were conducted on silty soils in the village of Gluchowo, located approx. $15 \mathrm{~km}$ from the centre of Poznań. It results from the archival analyses that soils from Głuchowo, lying immediately under the ground surface, were formed by accumulation and settlement under their own weight, thus they are probably normally consolidated deposits sensu stricte. The testing profile is composed of silty soils: silts, sandy silts, silty sands and loamy sands (Fig. 4a).

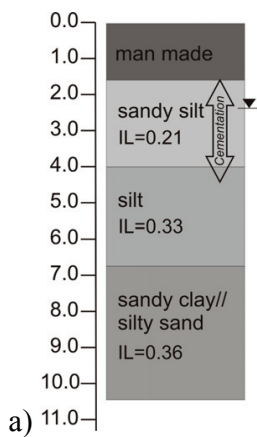

b)

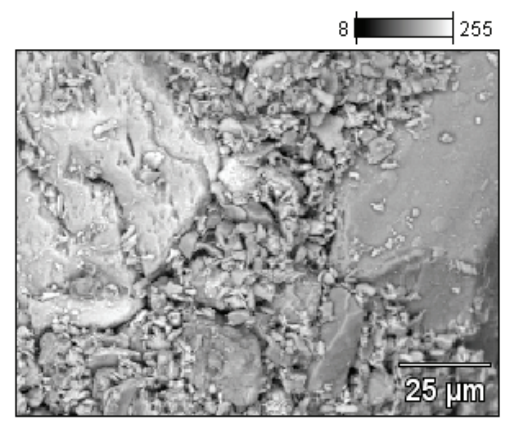

Fig. 4. The testing profile (a) SEM image of a soil sample (b) from the Głuchowo
The roundness of the deposits examined was assessed based on the analyses of images taken under a scanning microscope (Fig. 4b) and under an optic microscope. The roundness was analysed using the visual method, most frequently applying the model proposed by Powers [12] and the analysis of images showed that grains of the analysed deposits are rounded.

Moreover, it results from the microscopic analyses (SEM and SEM-EDS) that grains building the soil skeleton are loosely packed, with an unoriented structure.

Microscopic analyses clearly showed that in the upper part of the testing profile marked cementation zones are found, which further analyses showed to affect mechanical parameters of the soil investigated.

\section{ANALYSIS OF SHEAR STRENGTH IN SILTY SOILS}

Shear strength in the analysed silty soils was determined using three research methods. Vane test VT and tests in the triaxial compression apparatus TXT (consolidated undrained tests) were used as reference methods. Figure 5 shows results of strength testing by VT and TXT, which provided almost identical values of shear strength $s_{u}$.

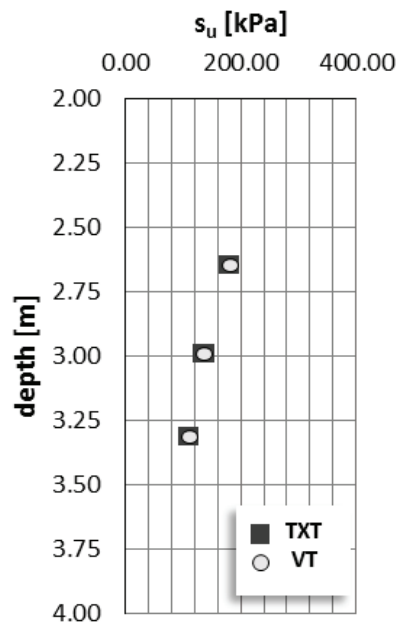

Fig. 5. A comparison of $s_{u}$ provided by reference methods

Applying different values of $N_{k t}$ recommended in related literature to calculate shear strength from CPTU the values of $N_{k t}$ were 10 and 24. Changes in undrained shear strength with depth were determined based on changes in cone resistance $q_{t}$ and calculated from equation (1). In order to illustrate how an erroneous assessment of shear strength may be obtained in 
silty soils when applying indiscriminately the recommended empirical coefficient $N_{k t}$ without performing reference tests, the values of $s_{u}$ are presented in Fig. 6a with the results of reference tests.

a)
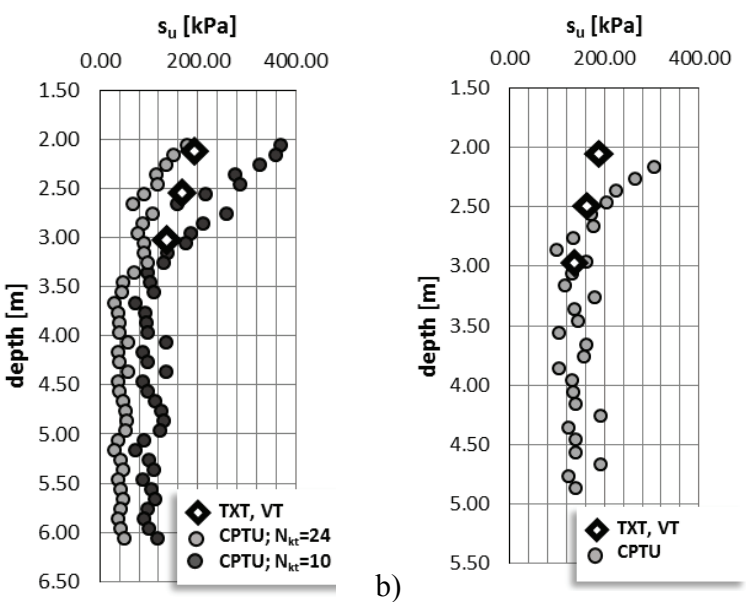

Fig. 6. A comparison of shear strength values from CPTU with results of reference tests

In the case of assessing shear strength in the silty deposits, the use of one coefficient for the entire testing profile, neglecting the geological history of subsoil, will probably result in the underestimation of $s_{u}$ values in the cementation zone and overestimation of these values outside this zone. Moreover, recorded values $s_{u}$ from CPTU (for $N_{k t}=10$ and 24) vary from the reference values of $s_{u}$ (VT and TXT).

Results of strength testing in the triaxial compression apparatus (TXT) and vane test (VT) made it possible to determine mean values of the empirical coefficient $N_{k t}$ separately in the cementation zone and outside it. For normally consolidated silty deposits values of the coefficient from reference tests $N_{k t}$ (TXT) and $\mathrm{N}_{\mathrm{kt}}$ (VT) were identical and ranged from 7 to 10 . In turn, values of $N_{k t}$ from both tests for soils in which carbonate cementation was identified were found to be 15.5. The cone factor $N_{k t}$ determined for cemented dusts is identical with values of $N_{k t}$ for silty overconsolidated deposits [13].

For the normally consolidated deposits the mean values of shear strength $s_{u}$ are strongly dependent on the range of the cementation zone. In view of these observations and the obtained discrepancies between $s_{u}$ values from CPTU and reference tests, the values of $s_{u}$ were determined again using new $N_{k t}$ values. In the calculations the mean $N_{k t}=15.5$ was applied for normally consolidated soils in the cementation zone and $N_{k t}=7 \div 10$ in the zone with no cementation (Fig. 6b).

The calculated mean value of shear strength $s_{u}$ in the cementation zone is $300 \mathrm{kPa}$, while outside this zone it is $148 \mathrm{kPa}$. The cementation zone is highly heterogeneous due to geological process (Fig. 7).

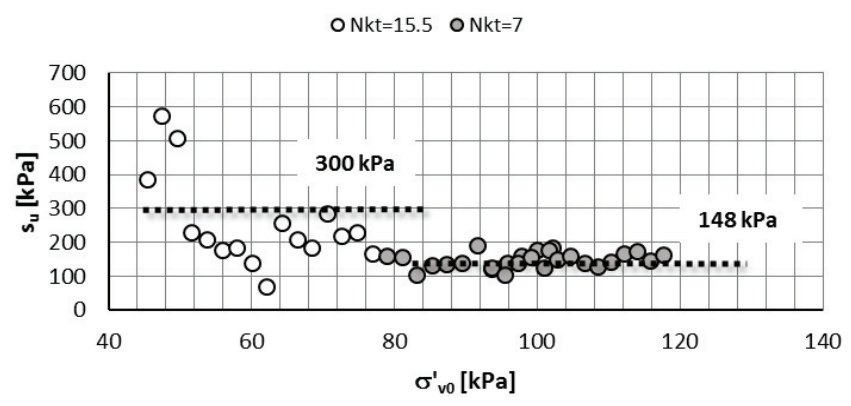

Fig. 7. A comparison of shear strength values from CPTU for recommended values of $N_{k t}$

\section{CONCLUSIONS}

The present analyses confirmed that assessment of the geological history of the analysed subsoil is an inseparable element of the appropriate assessment of mechanical parameters, e.g., through the value of the overconsolidation ratio OCR. This fact is evident in studies conducted on silty soils from the area of Poznań, in which the cementation zone was identified in the upper part of the testing profile.

The cone factor $N_{k t}$, which is used to determine undrained shear strength based on cone resistance should be related to the reference values from TXT and VT. Values of this coefficient differ highly significantly depending on the degree of subsoil overconsolidation and cementation. The author recommends the application of $N_{k t}$ ranging from 7 to $10 \mathrm{in}$ silty normally consolidated soils and $N_{k t}=15.5$ in cemented silty soils.

\section{REFERENCES}

[1] Kowalska M., Parametric identification of soil models in geotechnical problems, unpublished doctoral dissertation, Silesian University of Technology, Gliwice, Poland, 2009.

[2] MŁynarek Z., Sanglerat G., Relationship between shear parameters and cone resistance for some cohesive soils, Proc. of International Symposium In-situ Tests, Paris, 1983, Vol. 2, 347-352.

[3] MAYNE P.W., Interrelationships of DMT and CPT readings in soft clays, Proc. 2nd International Conference on Flat Dilatometer, 2-5 April 2006, Washington D. C., USA, 2006, 231-236.

[4] MŁynAReK Z., WierZBicki J., New approaches and investigation problems of in situ tests, Geologos, 2007, 11, 97-118.

[5] Senneset K., Janbu N., Svano G., Strength and deformation parameters from cone penetration tests, International Conference Penetration Testing, ESOPT '82, Balkema Publ., Amsterdam, Rotterdam, 1982, 863-870. 
[6] De Groot D.J., LutenegGer A.J., Characterization by sampling and in-situ testing Connecticut Valley varved clay, Studia Geotechnica et Mechanica, 2005, Vol. 27 (3-4), 107-120.

[7] Aas G., LaCASSE S., LunNe T., HoEg K., Use of in-situ tests for foundation design on Clay, Proc. of the ASCE Conference In-situ, 23-25 June 1986, Blackburg, Virginia, USA, 1986, 1-30.

[8] La Rochelle P., Zebdi M., Leroueil S., Tavenas F., Virely D., Piezocone tests in sensitive clays of eastern Canada, Proc. of the First International Symposium on Penetration Testing, ISPT-1, 1988, 21-24 March 1998, Vol. 2, Orlando, Florida, 831-841.

[9] Powell J.M., Quarterman R., The interpretation of cone penetration tests in clay with particular reference to rate effects, Proc. of the First International Symposium on Penetration Testing, ISPT-1, 21-24 March 1998, Vol. 2, Orlando, Florida, Balkema, 903-910.
[10] Bjerrum L., Problems of Soil Mechanics and construction on soft clays, General Report, 8th International Conference on Soil Mechanics and Foundations Engineering, Moscow, Russia, 6-11 August 1973, Vol. 3, 111-159.

[11] Lechowicz Z., WrZesińsKi G., Assessment of embankment stability on organic soils using Eurocode 7, Proc. of the 18th International Conference on Soil Mechanics and Geotechnical Engineering, Paris, France, 2-6 September 2013, $1827-1830$.

[12] Powers M.C., A New Roundness Scale for Sedimentary Particles, Journal of Sedimentary Petrology, 1953, Vol. 23 (2), 117-119.

[13] Stefaniak K., The selected alluvial subsoil as base material for the construction and earthen structures, unpublished doctoral dissertation, University of Life Sciences, Poznań, Poland, 2013. 